\title{
Memorias enfrentadas: las reacciones a los informes Nunca Más de Argentina y Chile
}

\author{
Fernando Camacho*
}

\section{RESUMEN}

Este artículo analiza las respuestas más inmediatas de los organismos de derechos humanos, las Fuerzas Armadas, los partidos políticos y la sociedad, una vez que fueron entregados el Informe de la Comisión Nacional sobre la Desaparición de Personas (Conadep) en Argentina y el Informe de la Comisión Nacional de Verdad y Reconciliación (CNVR) en Chile. La publicación de los informes resultó tener una gran trascendencia a nivel nacional puesto que por primera vez, y sólo un año después del restablecimiento de la democracia, se reconocieron de manera oficial las más graves violaciones a los derechos humanos cometidas durante las dictaduras precedentes. De este modo, cada uno de los cuatro sectores que son abordados en este trabajo adoptó una postura diferente frente al informe según sus reclamos e ideología política.

\section{Palabras clave}

Transición a la democracia $\bullet$ comisiones de la verdad $\bullet$ derechos humanos $\bullet$ memoria - reconciliación

Memories in conflict: Reactions on the 'never again' reports in Chile and Argentina

\section{ABSTRACT}

This paper analyzes the most immediate responses of human rights institutions, the Armed Forces, political parties, and society following the publication of the Report of the National Commission on the Disappeared (Conadep) in Argentina and the Report of the National

* Licenciado en Historia de América Universidad de Sevilla, doctor (c) en Historia Contemporánea Universidad Autónoma de Madrid y Pontificia Universidad Católica de Chile, convenio de cotutela de tesis. Profesor Departamento de Español, Portugués y Estudios Latinoamericanos Universidad de Estocolmo, Suecia. E-mail: camacho_f@lai.su.se. 
Commission for Truth and Reconciliation (CNVR) in Chile. The publication of these reports had a great national significance because, only one year after the reestablishment of democracy, they officially recognized the human rights violations committed during the preceding dictatorships. Each of the four sectors mentioned in this article responded to the reports in its own way, according to its demands and political ideology.

\section{Keywords}

Transition to democracy $\bullet$ truth commissions $\bullet$ human rights $\bullet$ memory

- reconciliation

\section{Introducción}

La entrega de los informes de la Comisión Nacional sobre la Desaparición de Personas (Condap) de Argentina y de la Comisión Nacional de Verdad y Reconciliación (CNVR) de Chile, ocasionó un gran impacto en ambos países. Si bien es cierto que la mayor parte de la sociedad tenía una idea del operativo de la represión, ahora todos los aspectos de las violaciones a los derechos humanos se difundieron masivamente de manera oficial.

En el caso de Argentina, toda la documentación fue entregada al Presidente Raúl Alfonsín el 20 de septiembre de 1984, la cual fue resumida en algo menos de 500 páginas y publicada bajo el nombre de Nunca más, también conocido como Informe Sábato. ${ }^{1}$ El número de desaparecidos que estableció el informe quedó fijado en 8.960, a pesar de constatar que "esta cifra no puede considerarse definitiva, toda vez que la Conadep ha comprobado que son muchos los casos de desapariciones que no fueron denunciados" (Conadep 1999:479). Igualmente, la comisión constató que existieron 340 centros clandestinos de detención a lo largo de todo el territorio nacional donde tuvieron lugar torturas y ejecuciones (Conadep 1999:479). La descripción detallada de los métodos de tortura que aparecía en el informe hizo que el centro de interés se desviara principalmente al "Show del horror", 2 de manera que no llegó a producirse un debate social ni político importante sobre el contenido del informe.

En Chile, el informe de la CNVR fue conferido al Presidente Patricio Aylwin el 9 de febrero de 1991 (conocido como Informe Rettig). ${ }^{3}$ No obstante, Aylwin no lo hizo público hasta el 5 de marzo, después de leerlo detenidamente durante sus vacaciones de verano. El informe estableció que el número de víctimas causadas durante la dictadura fueron 2.298 (Informe de la CNVR 947). ${ }^{4}$ Posiblemente, el motivo de tal periodo de

El presidente de la Conadep fue el escritor Ernesto Sábato.

2 El "Show del horror" fue el calificativo que recibió el hecho de que los medios de comunicación mostraran públicamente cada uno de los procedimientos de tortura utilizados por las Fuerzas Armadas en Argentina.

3 El presidente de la CNVR fue el jurista Raúl Rettig.

4 Al finalizar la comisión, sus integrantes recomendaron al gobierno que continuara con las investigaciones de 
Vol. XXII / № 2 / 2008 / 67-99

silencio se debió a la intención de enfriar el debate que giraba en torno a la comisión antes de que la tensión se pusiera demasiada alta (Barahona de Brito 1997:169). Finalmente, Aylwin presentó el informe a todo Chile en una ceremonia transmitida por televisión en el que se hacía un llamamiento a la reconciliación, además de pedir perdón en nombre del estado por las graves violaciones a los derechos humanos cometidos durante el período de la dictadura. A diferencia de lo que sucedió en Argentina, en Chile el debate político sobre el contenido del informe estuvo más presente.

Los informes fueron acompañados de una explosión de memoria en ambos países (Camacho 2006b:27). Cada individuo, cada grupo y cada organismo recordaba sus vivencias pasadas con el fin de relacionarlas con los hechos que se describían en los informes. Si bien hubo una aceptación mayoritaria, la disconformidad también estuvo presente en los meses posteriores al conocimiento de los informes, especialmente en los sectores protagonistas de los hechos ocurridos, tanto víctimas como victimarios. Así, se criticaron las interpretaciones y las conclusiones de los informes sobre la estrategia represiva castrense, pero en ningún momento se pudo desmentir un solo caso de los narrados. Ahora, y desde la base de esta certeza, los distintos argumentos giraron alrededor de las circunstancias que habían favorecido y propiciado las violaciones a los derechos humanos.

El objetivo de este artículo es mostrar las reacciones inmediatas a las entregas de los informes por parte de los organismos de los derechos humanos, las Fuerzas Armadas, los partidos políticos y la ciudadanía común, entendiéndola como el grupo mayoritario que no tuvo una responsabilidad directa en lo ocurrido durante la dictadura. Puesto que se trata de una investigación empírica, se han consultado fundamentalmente archivos de organismos de derechos humanos de Chile y Argentina junto con recortes de prensa. Sin que exista una amplia bibliografía sobre las reacciones a la Conadep y la CNVR, los autores aquí mencionados se encuentran entre quienes más las han investigado, tales como Elizabeth Lira, Brian Loveman, Sandrine Lefranc, Hugo Vezzetti, Luis Roniger, Mario Sznajder, Tomás Moulián, Horacio Verbistky y Fernando Camacho, entre otros.

\section{Organismos de Derechos Humanos: gratitud y crítica}

Los organismos de derechos humanos encontraron en la publicación de los informes de las comisiones el punto más alto del debate nacional sobre el problema de las violaciones a los derechos humanos.

las violaciones a los derechos humanos al considerar que no habían tenido el suficiente tiempo para resolver cientos de casos que les habían sido presentados. Aylwin dio luz verde a la propuesta y creó la Corporación Nacional de Reparación y Reconciliación (CNRR), la cual logró establecer que el número de víctimas mortales era más alto que el presentado por el Informe Rettig, fijándose en 3.197 casos (CNRR 1996). 
A nivel general se agradecieron los esfuerzos de los comisionados y de los respectivos gobiernos por haber creado dichas comisiones. Lo común fue una gratitud acompañada de demandas de justicia.

Las críticas, si bien fueron menos frecuentes, también se produjeron por parte de personas clave. Ciertos organismos se mostraron cautelosos ya que no compartían plenamente los hechos e interpretaciones que se difundían en tales informes. La principal crítica se centró en la ausencia de listados de los represores y en los antecedentes históricos a la represión narrada en las primeras páginas de los informes.

\section{Los organismos de derechos humanos ante el Nunca más en Argentina}

Durante las semanas previas a la entrega del informe de la Conadep había una enorme expectación. No obstante, casi la totalidad de los organismos de derechos humanos sabían que los nombres de las personas involucradas en la represión no serían incluidos en el informe, ya que varios de los integrantes de la Conadep eran miembros de dichas instituciones. Parece ser que la razón de Alfonsín de no incluir el listado de los nombres en el informe final de la Conadep se encontró con las presiones ejercidas por las FFAA para que eso no ocurriera (Verbistky 2004).

El 20 de septiembre de 1984, Sábato entregó a Alfonsín el informe de la comisión. Ese día, los organismos de derechos humanos convocaron una concentración para respaldar dicha ceremonia, a la que acudieron cerca de 70.000 personas.

La única organización que se negó a acudir a la manifestación fue Madres de Plaza de Mayo, aunque algunas de sus integrantes sí se acercaron de manera individual al acto. Según la presidenta Hebe de Bonafini: "No fuimos a la marcha de apoyo al informe Sábato porque no estábamos de acuerdo en que no se dieran los nombres de los militares incluidos en el documento" (Clarín, 23 de septiembre de 1984). Además, todavía reclamaban por una comisión bicameral y aún desconocían el contenido del informe. Madres de Plaza de Mayo criticó el libro Nunca más argumentando que "interpretaciones tendenciosas y falsas conclusiones terminan convirtiendo al informe elaborado por la Comisión Nacional sobre la Desaparición de Personas en un certificado de defunción masiva, con el que se pretende cerrar la mayor tragedia de la historia argentina" (Madres de Plaza de Mayo 1985:7).

Así, las Madres rechazaban categóricamente el prólogo de Sábato, donde afirmaba que Argentina vivió convulsionada por el terror causado tanto por la extrema izquierda como por la extrema derecha, interpretación que sería conocida como la 'teoría de los dos demonios'. Tampoco aceptaron la conclusión del informe donde se suponía que los desaparecidos estaban muertos, porque consideraban que tal declaración cerraba el problema en forma definitiva. 
El Servicio de Paz y Justicia (Serpaj), liderado por Adolfo Pérez Esquivel, no estuvo de acuerdo con la política de derechos humanos de Alfonsín, pero optó por sumarse a la marcha del 20 de septiembre. No obstante, a diferencia de los restantes organismos de derechos humanos, prefirió incluir su nombre en la convocatoria oficial.

La Asamblea Permanente por los Derechos Humanos (APDH), el Movimiento Ecuménico por los Derechos Humanos (MEDH) y la Liga Argentina por los Derechos del Hombre (LADH), elaboraron una declaración conjunta para el día de la marcha en la cual respaldaban el informe. El título fue "Hacia la verdad y por la justicia", que señalaba:

las entidades convocantes a la marcha que se realizará el próximo jueves 20 en apoyo al informe que la Comisión Nacional sobre Desaparición de Personas entregará al presidente Raúl Alfonsín, sostuvieron hoy, en una declaración conjunta, que las pruebas reunidas por el organismo que preside el escritor Ernesto Sábato se constituyen en una exigencia de justicia que implica la necesaria investigación y sanción judicial ante los jueces de la Constitución de los responsables de crímenes de lesa humanidad, que no pueden ni deben quedar impunes. (Documento B.758, "Hacia la verdad y por la justicia", Archivo APDH)

La principal reivindicación de estos organismos se centró en juzgar a los responsables de la represión, ya que sus causas todavía estaban en manos de los tribunales militares. APDH y MEDH habían sido dos de las instituciones que colaboraron más directamente con la Conadep, puesto que varios de sus integrantes se convirtieron en personal de la comisión. Por esta razón, no se produjo crítica alguna hacia la labor de la Conadep.

La agrupación Familiares de Detenidos Desaparecidos por Razones Políticas (FDDRP) también se adhirió a la marcha que acompañó al Nunca más. Entre sus reclamos resaltaba la proclama de aparición con vida de los desaparecidos, al igual que hacían las Madres de Plaza de Mayo. En una carta a Sábato, destacaron:

valoramos altamente la dedicación incondicional y el espíritu humanitario y ético con que han asumido esta responsabilidad todos y cada uno de los que han integrado la CONADEP y por ello queremos expresarles nuestro reconocimiento. Creemos que este trabajo debe ser la base para: * la Respuesta a nuestro reclamo de Aparición con Vida. * el Juicio y Castigo a los Culpables. Es con estas consignas que estaremos en la Plaza de Mayo el jueves 20 en oportunidad de que esa Comisión haga entrega al Poder Ejecutivo del fruto de su labor. (Documento C4.36. "Al Presidente de la Comisión Nacional sobre Desaparición de Personas Sr. Ernesto Sábato. 14 de septiembre de 1984”, Archivo FDDRP) 
Con los años, los organismos de derechos humanos casi en su totalidad defendieron y auspiciaron el informe Nunca más en sus continuas reediciones con un énfasis todavía mayor que en su primera publicación. Parece que el tiempo borró las limitaciones del informe y potenció sus virtudes, muy posiblemente debido al efecto que causó en la sociedad argentina en los años posteriores a su divulgación. En una declaración conjunta elaborada por Abuelas de Plaza de Mayo, APDH, Centro de Estudios Legales y Sociales (CELS), FDDRP, LADH, Madres de Plaza de Mayo (línea fundadora), MEDH, Serpaj y Asociación Ex Detenidos Desaparecidos, se aclaró:

Los organismos de Derechos Humanos saludamos la reedición del Informe de la CONADEP publicado bajo el significativo título de NUNCA MÁS [...]. El NUNCA MÁS nos narra la historia del terror planificado desde el poder del Estado y ejecutado por las fuerzas armadas y de seguridad. Sus páginas son registros de secuestros, torturas, violaciones y exterminio de prisioneros indefensos. También de secuestros de niños nacidos y por nacer. Por eso esta reedición del testimonio del horror era necesaria, porque ayuda al recuerdo y el recuerdo ayuda a la conciencia y la conciencia impulsa la lucha por la justicia y la justicia, la JUSTICIA de verdad, es la única garantía del NUNCA MÁS. (Documento B8.95. "Por la memoria histórica - contra la impunidad", Archivo FDDRP)

Los organismos confiaron en que una mayor divulgación pública de la verdad favorecería que la sociedad argentina presionara al gobierno para procesar a los responsables de las violaciones a los derechos humanos.

\section{Los organismos de derechos humanos ante el Informe de la CNVR en Chile}

Durante las semanas previas a la entrega del informe, los organismos de derechos humanos fueron mostrando una actitud bastante cautelosa dado que sospechaban cuál iba a ser su contenido. Por ello convocaron una movilización frente a La Moneda el día en que se entregaba el informe al Presidente Aylwin para reivindicar la verdad, la justicia y el castigo para los represores.

Una vez conocido el contenido del informe de la CNVR, se dieron dos tendencias opuestas. Por un lado, los organismos de derechos humanos y la Iglesia Católica aceptaron casi mayoritariamente el trabajo de la comisión. Las asociaciones de familiares y víctimas de la represión, por el contrario, fueron más aprensivas (Barahona de Brito 1997).

El organismo que adoptó la actitud más pro gubernamental fue la Comisión Chilena de Derechos Humanos (CCDH). Su presidente, Jaime Castillo, había integrado la CNVR. Semanas después de la entrega del informe al Presidente, Castillo aclaró: 
Me parece que el informe es imparcial, serio y fundamentado, y da a conocer la verdad. Creo que el país debe asumir las consecuencias de esta verdad y disponerse al objetivo final, que es el restablecimiento pleno de la democracia, el espíritu de reconciliación y los acuerdos sociales y políticos que permitan adelantar en esta materia. (La Tercera, 26 de febrero de 1991)

La CCDH señaló que el Informe "permitiría que todos los sectores pudieran llegar a saber que en el pasado se produjeron graves violaciones de derechos humanos" (Loveman y Lira 2002:524-525). Asimismo, era partidaria de procesar a las personas involucradas en las violaciones a los derechos humanos ocurridas durante la dictadura. Jaime Castillo destacó: "la falta de justicia puede provocar hechos de violencia y pidió a los Tribunales acelerar los procesos para dar paso a las otras etapas que se establecen en el Informe de la Comisión" (La Época, 4 de mayo de 1991).

A finales de febrero del mismo año, Aylwin se reunió con las asociaciones de familiares de víctimas de la represión, la AFDD y la Agrupación de Familiares de Ejecutados Políticos (AFEP) para hablar del informe de la CNVR antes de su difusión.

La AFDD mantuvo una posición algo más crítica hacia el informe, aunque lo valoró de manera positiva. Además de exigir los nombres de los responsables, el fin de la ley de amnistía y una política de reparación, buscaban unas soluciones más acorde con las consignas de su grupo. Según Sola Sierra: "No nos sirven soluciones globales. Si nuestros seres queridos están muertos, no nos satisface el conocimiento moral del hecho sino la concreción de la muerte, o sea, saber dónde están sus restos" (La Tercera, 26 de febrero de 1991). La AFDD compartió las conclusiones del informe, especialmente la referida a la responsabilidad del Poder Judicial por negar protección a las víctimas durante la dictadura.

El líder de AFEP, Hugo Cármano, marcó la necesidad de llevar a los tribunales a las personas involucradas en la represión ilegal, pero ello no sería posible si "no se reestructura profundamente el Poder Judicial y se democratizan las Fuerzas Armadas" (Documento 002000, "Carta a Patricio Aylwin de la Agrupación de Familiares de Ejecutados Políticos, 11 de junio de 1991”, Archivo Corporación Justicia y Democracia). Además, la AFEP exigió la verdad completa en cuanto a la publicación de los nombres de los agentes con delito de sangre, el fin de la ley de amnistía y medidas de reparación.

El Codepu valoró positivamente el informe. En su declaración pública destacó que: "El Informe de la Comisión Nacional de Verdad y Reconciliación constituye [...], el más importante aporte estatal a la necesaria tarea de reconstrucción de la memoria histórica nacional. [...] el Informe constituye un muy valioso instrumento para estudiar nuestra historia más reciente" (Codepu 2001:245).

El cardenal Raúl Silva Henríquez, fundador de la Vicaría de la Solidaridad, valoró el informe de la CNVR "como bueno" y declaró que los contenidos del documento eran "tristes, porque da a conocer muchas cosas que jamás habían pasado en nuestra tierra" 
(La Época, 7 de marzo de 1991). El cardenal se refería a que nunca en la historia del país habían sucedido hechos similares.

La Vicaría de la Solidaridad se pronunció favorablemente sobre el informe de la CNVR. Su presidente, Sergio Valech, destacó:

El Informe de la Comisión Verdad y Reconciliación inicia el debate público sobre la temática de los Derechos Humanos, que estuvo en gran medida silenciada y censurada durante el régimen anterior [...]. Este documento entrega un conjunto de antecedentes que nos pueden ayudar a entender las violaciones extremas a los derechos humanos ocurridas bajo el gobierno militar $\mathrm{y}$, además, otorgar algunos elementos para la posibilidad de abrir espacios para el reencuentro social entre los chilenos. (Documento 00044.00. "Verdad y reconciliación. Elementos para una reflexión a partir del Informe de la Comisión Verdad y Reconciliación”, Archivo Vicaría de la Solidaridad)

Resulta interesante observar que Valech destaca que el informe sirve para comprender "las violaciones extremas a los derechos humanos", es decir, únicamente aquellas con resultado de muerte, dejando de lado todos los otros casos que no tuvieran ese destino fatal.

\section{Las Fuerzas Armadas: la justificación}

La evidencia de los hechos presentados en los informes hizo que las FFAA no pudieran mantener la negación de las violaciones a los derechos humanos. El discurso militar respecto del tema se modificó para intentar justificar con varios argumentos lo que ya era innegable. Por un lado, acentuaron la idea de un enfrentamiento de guerra civil y, por el otro, el desorden social y la crisis económica ocasionada por la subversión (Marchesi 2005). De este modo, y para devolver la estabilidad al país, no quedó otra alternativa que reprimir con dureza, siendo esta la idea que legitimó a los militares el estar en el gobierno por tanto tiempo.

A partir de entonces se asumían los aspectos legales del combate contra la subordinación. Se intentó demostrar que las torturas, los crímenes y las desapariciones fueron fruto de excesos individuales perpetrados por miembros de las FFAA que actuaron por cuenta propia. El objetivo era librar a los altos oficiales de toda culpa. Por el contrario, los bajos y medios oficiales empezaron a declarar que únicamente obedecieron órdenes y que aplicaron las técnicas aprendidas en las academias militares. Se pasó de la negación a una justificación llena de contradicciones entre las distintas voces de los implicados.

En cualquier caso, la explicación de los excesos no resultó convincente para la sociedad, ya que en el hipotético caso de que así hubiera sido, ni un solo secuestro fue impedido por la policía o el ejército, ni un solo centro de detención descubierto ni un preso 
rescatado, y tampoco la noticia de una condena a los responsables de estos delitos. Además, esto había ocurrido en países claramente controlados por las fuerzas de seguridad, lo cual demuestra que se trataba de un plan represivo organizado, dirigido y ejecutado meticulosamente por los dirigentes.

\section{Las FFAA argentinas frente al Nunca más}

El informe de la Conadep fue asumido en silencio por las FFAA tras su inmediata difusión. Ninguna de las distintas ramas hizo un pronunciamiento público que contradijera su contenido, pero tampoco reconocieron lo que en él se narraba. En principio, las FFAA estaban subordinadas al poder civil y no gozaban del respaldo suficiente para poder criticarlo. De ese modo, optaron por guardar silencio. Sin embargo, el Tribunal Militar, que hasta el momento era el único organismo capaz de juzgar a los responsables de la represión, el 25 de septiembre de 1984, a los pocos días de la entrega del informe, mandó una carta a la Cámara Federal. En ella se exponía una serie de argumentos para evitar el procesamiento de sus compañeros. El documento establece lo siguiente:

En conclusión el tribunal quiere poner de manifiesto que no se considerará en condiciones de sentenciar en esta causa dentro del plazo previsto, porque interpreta que sin el panorama completo, descubierto a la luz de los hechos probados, le resultará imposible formar una opinión afirmada en la verdad, ni dimensionar debidamente las responsabilidades de quienes obraron o pudieron haber obrado por motivaciones que enmarcaron en la lucha contra la delincuencia subversiva y terrorista que asoló a nuestra patria y, hacerlo además, sin perder de vista el concepto de la disciplina, bien jurídico que configura la base inconmovible de las instituciones militares y, justifica en última instancia, la existencia de los tribunales militares. (Rama Argentina de la Asociación Americana de Juristas 1988:36)

Después de esta declaración, el gobierno optó por delegar a los tribunales civiles los casos de violaciones a los derechos humanos, lo cual se materializó por primera vez con el juicio a la Junta Militar iniciado en abril de $1985 .^{5}$

5 El juicio finalizó el 9 de diciembre de 1985. Las sentencias fueron: general Videla y almirante Massera cadena perpetua, general Viola a 17 años de cárcel, almirante Lambruschini a 8 años de reclusión, y el brigadier Angosti a 3 años y 9 meses. General Galtieri, almirante Anaya, brigadier Lami Dozo y brigadier Graffigna fueron absueltos. 
Durante todo este período, los uniformados actuaron clandestinamente amenazando y atentando contra ex miembros de la Conadep y figuras clave de organismos de derechos humanos. De la misma manera, intentaron impedir que agentes arrepentidos entregaran información sobre el operativo represivo. Inclusive se robaron testimonios de sobrevivientes en un juzgado de Rosario.

Algunos militares, sectores de extrema derecha y familiares de uniformados asesinados por grupos de extrema izquierda durante los años 70, formaron la asociación Familiares y Amigos de los Muertos por la Subversión (Famus). Famus empezó a emitir pronunciamientos justificatorios de la acción represiva del proceso por haber devuelto la estabilidad al país. Por lo general sus comentarios fueron también dirigidos en contra de los familiares de las víctimas del terrorismo de estado. Mientras se procesaban las juntas militares, el Famus se dedicó a organizarles misas y velorios.

Desde mediados de 1984 y según se iba consolidando la democracia, dentro de las FFAA argentinas se empezaron a gestar divisiones profundas debido a la gravedad de los hechos. Un sector de militares en retiro, en su mayoría simpatizantes del peronismo, se agrupó en el Centro de Militares para la Democracia Argentina (Cemida). Desde entonces han publicado informes condenando las violaciones a los derechos humanos, lo que no agradó a muchos uniformados del otro sector.

Los responsables directos no formaron ninguna asociación, pero por lo general se concentraron alrededor del Círculo Militar. Si bien el número de oficiales que estuvo envuelto en tareas represivas es muy alto, sólo un militar se ha destacado por recoger la voz de todos. Se trata del general de División (R) Ramón Díaz Bessone, quien en 1976 fue ministro de Planeamiento de la Nación y además estuvo interinamente a cargo de la Presidencia del país de manera temporal. Poco después del juicio a la Junta Militar (1986) publicó Guerra revolucionaria en la Argentina (1959-1978). Con este primer libro pretendía reivindicar la actitud 'heroica' de las FFAA argentinas en la lucha contra la insurrección. En su segunda edición, Bessone señala de la Conadep: "tribunal inquisidor de naturaleza no legal, sino política, cuyo juicio moral ya fue hecho y cuyo juicio real aguarda el curso de la historia" (Díaz Bessone 1996:310).

Reynaldo Bignone, último dictador del proceso, tampoco guardaba para sí sus rencores hacia la labor de la Conadep. En sus memorias afirma:

Se llegó a crear un muy original organismo denominado CONADEP [...] cuyo cometido fue recibir testimonios, y darlos por ciertos sin mayor análisis ni requerimiento de pruebas, acerca de atrocidades cometidas durante la dictadura. Toda esta retahíla de afirmaciones fue compendiada en tiempo récord y dada a conocer en un libro titulado Nunca más, que se distribuyó a un precio ínfimo y hasta llegó a regalarse en las escuelas. (Bignone 2000:186) 
La policía, al igual que las FFAA, se sintió ultrajada con el trabajo de la Conadep. Miguel O. Etchecolatz, director general de Investigaciones de la Policía de la Provincia de Buenos Aires entre 1976-1979 y mano derecha de Ramón Camps, ${ }^{6}$ lanzó los mayores comentarios jamás emitidos en contra del Nunca más:

Oportunamente, previa instrumentación sujeta a satisfacer necesidades de orden político e ideológico, el gobierno de turno alentó e impulsó la aparición del libro NUNCA MÁS, lanzado con ampulosa y desorbitada divulgación [...]. Esa intención adquirió un vuelo por encima de lo que es un justo reclamo, que trasponía la barrera de la razón asentando sus pies en el mojón de esa astuta maniobra: LA VENGANZA. Entiendo, que el Dr. Raúl Alfonsín, los componentes de la CONADEP, los miembros de la Excelentísima Cámara Federal y Fiscales de Cámara, no despertaron una mañana concibiendo la misma idea que los identificara para poner en práctica un plan de desprestigio a las fuerzas que defendieron la Patria en momentos difíciles, sometiendo a un juicio inconstitucional y condenando a quienes fuimos protagonistas en el campo de batalla. (Etchecolatz s/f:7)

A pesar de este conjunto de comentarios despectivos en contra del informe Nunca más, ningún autor desmiente un solo caso presentado.

\section{Las FFAA chilenas frente al informe de la CNVR}

A diferencia del caso argentino, las distintas ramas de las FFAA chilenas sintieron el deber de pronunciarse sobre el trabajo de la CNVR. Esta situación reflejaba su grado de autonomía para contradecir al gobierno electo en aquellos puntos que consideraba necesario.

La característica de aquel momento era ver a las FFAA actuando como si fueran un partido político de oposición. Pinochet, desde su lugar como comandante en jefe, hacía permanentes declaraciones sobre las distintas materias de gobierno. Sin duda que el Plebiscito de 1988, en el cual la sociedad básicamente tuvo que elegir entre la institución castrense y la Concertación, influyó en su imagen de las FFAA como actor político.

La actitud de las FFAA, nada más difundirse el informe, fue de guardar silencio a la espera de un análisis en profundidad de su contenido. Aun así, Pinochet hizo saber su preocupación por los casos de violaciones a los derechos humanos que la CNVR había entregado a los tribunales de justicia, puesto que temía por el procesamiento de sus hombres:

6 General y jefe supremo de la Policía de la Provincia de Buenos Aires durante los primeros años del proceso y máximo responsable de las acciones de su cuerpo. 
A lo anterior, se suma una serie de trascendidos relacionados con los casos entregados por la Comisión Rettig a la justicia lo que, si bien no dan a conocer identidades de supuestos autores de los hechos, entregan otros antecedentes que permiten establecer suposiciones con las potenciales consecuencias trágicas que de ello se podrían derivar en perjuicio de personal militar. (Documento 007062, "Carta del Comandante en Jefe Augusto Pinochet al Presidente Aylwin", Archivo Corporación Justicia y Democracia)

Lo primero que hicieron las Fuerzas Armadas fue pasar el informe a sus asesores para que empezaran a analizar su contenido, además de expresar "su irrestricta lealtad hacia el Comandante en Jefe del Ejército" (Documento 003021, Archivo Corporación Justicia y Democracia). Curiosamente, cada análisis de las ramas castrenses tiene considerables diferencias tanto en su forma como en su contenido. Los más duros fueron el Ejército y la Armada. Carabineros también se justificó y criticó las conclusiones del informe, aunque más suavemente. La Fuerza Aérea (FACH) mostró una mayor adhesión a Aylwin.

La primera respuesta la efectuó la FACH en boca del comandante en jefe Fernando Matthei, el 8 de marzo de 1991, tan sólo cuatro días después de la entrega del informe. En primer lugar, Matthei mostraba su total adhesión al marco histórico del informe donde se aclaraba que la degradación de la situación política, social y económica a la que se había llegado en 1973 dio lugar al golpe del 11 de septiembre. Esta parte fue escrita por el historiador conservador Gonzalo Vial, integrante de la CNVR nombrado por Aylwin para lograr el reconocimiento de la derecha y justificar así la llegada de los militares al poder (Camacho 2006a). Igualmente, Matthei apoyó la iniciativa presidencial:

El informe de la Comisión no puede ser analizado y comprendido sin referirse a la grave crisis política, social y económica que sufría el país al 11 de septiembre de 1973, situación que está certeramente descrita en el capítulo I Marco Político [...].

3. Lamentamos hoy, como lo hemos lamentado siempre, toda pérdida de vida humana. Las víctimas civiles y militares de esta desafortunada etapa representan un testimonio de extremo sentimiento para nuestra conciencia, con las consecuencias de dolor que acarrea para una nación el abandono de una convivencia regida por la razón, que obliga al empleo de la fuerza [...].

4. Estimo que la amplia mayoría de los chilenos hemos reconocido el esfuerzo del Presidente Aylwin para buscar la reconciliación que permita proyectar a Chile a un futuro superior. (El Mercurio, 9 de marzo de 1991)

Posteriormente, Carabineros respondió a través de un comunicado realizado por el general Rodolfo Stange el 22 de marzo. La obstinación se mostró en la divulgación de la situación previa al 11 de septiembre de 1973, y en no prejuzgar verbalmente a nadie por 
violaciones a los derechos humanos, aunque se apoyó a Aylwin en el objetivo de lograr la reconciliación:

3. Necesario es señalar que los hechos descritos en el Informe no pueden entenderse desvinculados de la realidad jurídica, política y social imperante en el periodo previo al 11 de septiembre de 1973, tal como lo expresa la Comisión y, su juzgamiento definitivo corresponderá a los órganos jurisdiccionales, de acuerdo al ordenamiento vigente. En tal predicamento, Carabineros de Chile reitera que no puede aceptar el prejuzgamiento individual ni colectivo de su personal, tanto en servicio activo como de quienes se encuentran en situación de retiro, mientras no se acredite suficiente responsabilidad penal por tribunal competente.

6. Carabineros de Chile declara su más decidido apoyo a los objetivos de justicia, reconciliación y el bien común para la patria y cada uno de sus hijos. Sin distingos de ninguna especie y al servicio de tales fines, ha puesto sus mejores esfuerzos cumpliendo fielmente las funciones de dar eficacia al derecho, garantizar el orden público y la seguridad pública interior.

7. La institución adhiere plenamente al llamado efectuado por el Excelentísimo señor Presidente de la República, don Patricio Aylwin Azócar, en orden a que, todos juntos, hagamos lo necesario para sanar las heridas del pasado y construir un futuro de justicia, de progreso y de paz para Chile. (El Mercurio, 23 de marzo de 1991)

El 27 de marzo, los comandantes en jefe del Ejército, de la Armada y el director general de Carabineros, fueron convocados por el Presidente Aylwin a una reunión del Consejo de Seguridad Nacional para que se le entregaran las distintas opiniones sobre el informe de la CNVR. En ese momento fueron expuestas por primera vez las respuestas del Ejército y la Armada, quienes hasta ese momento no habían emitido un comunicado oficial.

Horas después de la reunión del Consejo de Seguridad Nacional, Pinochet anunció la postura del Ejército en el Aula Magna de la Escuela Militar frente a más de mil uniformados. Se trató de la respuesta más larga entre todas las emitidas, a través de la cual se exponía una total discrepancia respecto del informe. Además se le negaba toda "validez histórica como jurídica” (La Nación, 28 de marzo de 1991). En su declaración final, Pinochet enfatizaba:

1. El Ejército, junto a las demás instituciones de las Fuerzas Armadas y Carabineros, fue llamado a intervenir en la más grave crisis institucional sufrida por el país en el presente siglo [...]. El Ejército de Chile ciertamente no ve razón alguna para pedir perdón por haber tomado parte en esa patriótica labor. 
2. Una Comisión formada por ciudadanos entre los cuales hay quienes ostentaron por años una conocida animadversión hacia las Fuerzas Armadas y Carabineros y hacia su gobierno, carece de la imparcialidad necesaria como para erigirse en instancia capaz de determinar la verdad de hechos sometidos a su conocimiento y que envuelven a un juzgamiento de la actuación de los hombres de armas [...]. El Ejército rechaza la utilización político-partidista del Informe y la amplia cobertura internacional que se está procurando darle [...].

4. De una manera muy especial, el Ejército rechaza la conclusión de la referida Comisión en el sentido de que no hubo en el país un estado de guerra $[\ldots]$.

8 El Ejército de Chile declara solemnemente que no aceptará ser situado ante la ciudadanía en el banquillo de los acusados, por haber salvado la libertad y la soberanía de la patria a requerimiento insistente de la civilidad. (La Nación, 28 de marzo de 1991)

En el discurso se observa con claridad la justificación de todas las acciones militares. Se criticó también a los integrantes de la CNVR y el contenido del informe. Igualmente, Pinochet defendió la idea de la guerra civil y expuso que no iba a permitir que ninguno de sus soldados fuera procesado.

La Armada, a través del comandante en jefe, almirante Jorge Martínez Bus, presentó su respuesta con el documento más fundamentado entre todos los demás desde el punto de vista doctrinario. Su declaración es considerablemente larga y crítica contra la labor de la comisión, aunque algo más suave que la emitida por el Ejército. Los otros comentarios exponen la misma línea que siguió el resto de las instituciones, como la justificación al golpe de estado, la guerra civil, la obra del régimen militar y su deseo en lograr la reconciliación:

el caso de Chile, en los años que siguieron al pronunciamiento del 11 de septiembre de 1973, constituyó un ejemplo típico de un estado de guerra interna, en el que la junta de gobierno estaba permanentemente enfrentada a la encornada acción revolucionaria de grupos violentistas organizados, cuyo objetivo final era el de derrocar el régimen, implantar un sistema totalitario, destruir la libertad y la soberanía de nuestra patria y los grandes valores espirituales e históricos que identifican nuestra nacionalidad. (La Nación, 28 de marzo de 1991)

En ninguna de las respuestas de las FFAA se pudo desmentir las violaciones a los derechos humanos y mostraron su interés en lograr la reconciliación a pesar de no compartir el camino elegido por Aylwin para conseguirlo. Moulián considera que la estrategia 
de reconciliación de la Concertación falló "porque las FFAA no reconocieron la legitimidad del gesto que acompañó al Informe Rettig” (Moulián 2000:25). De la misma manera, las FFAA tampoco pidieron perdón a las víctimas ni reconocieron la gravedad de las violaciones a los derechos humanos. Además, pusieron en duda la imparcialidad de la comisión y de buena parte de sus miembros. Asimismo, criticaron su metodología y sus conclusiones.

\section{Los partidos políticos: asunto resuelto}

Una vez que fueron entregados los informes, el conjunto de los partidos políticos sintió que la verdad había sido finalmente expuesta a pesar de las tareas pendientes en materias de reparación, exhumaciones, continuación en la búsqueda de los desaparecidos y procesos a los responsables de las violaciones a los derechos humanos. La base y punto de partida para todo ello había sido construida. A partir de ahí se pensó que el resto de las medidas se lograrían con menos dificultad. El debate político más intenso se cerró una vez entregados los informes, al pensar que quedaba aclarada o respondida la demanda de la mayor parte de la ciudadanía.

\section{Los partidos políticos frente al Nunca más en Argentina}

El debate político que se dio en torno al informe de la Conadep no tuvo gran resonancia. El informe era el trabajo final de una comisión cuya naturaleza había sido cuestionada por la mayor parte de los partidos representados en el Congreso debido a los límites que la condicionaban. La Conadep no se trató de una comisión bicameral, tal como demandaban el Partido Intransigente, la Democracia Cristiana o el Partido Justicialista, pero la entrega del informe supuso el fin de la discusión al quedar cerrada la posibilidad de cambio. En todo caso, un último intento de conseguir la creación de una comisión bicameral se produjo el mismo día de entrega del informe a Alfonsín:

Finalizado el mitin de Plaza de Mayo los partidos de izquierda, algunos sectores del justicialismo y las organizaciones promotoras de los derechos humanos marcharon hacia Tribunales y el Congreso en apoyo de su reclamo de integración de una comisión parlamentaria bicameral para la atención del tema de los excesos represivos. (Tiempo Argentino, 21 de septiembre de 1984)

En esta nueva etapa, el contenido del Nunca más no se debatió en el Congreso ni en el Senado, si bien le fue dado a conocer. El informe fue aceptado por la totalidad de los partidos políticos sin poner en duda lo que en su interior se narraba. No había sector 
alguno en las cámaras que hubiera colaborado con la dictadura, por lo que nadie se sintió aludido.

La poca crítica vino principalmente de la oposición de izquierda, al no incluirse el listado de los nombres de los responsables a las violaciones a los derechos humanos.

El democratacristiano Augusto Conte, principal defensor de los derechos humanos en el Congreso, reconoció el valor del informe. Conte consideró que a partir de ese momento se iniciaba una fase reivindicativa de los derechos humanos. Para ello lideró una campaña de presión al gobierno con la colaboración de los distintos organismos de derechos humanos para que se creara una nueva comisión de la Cámara Baja. Desde el trabajo realizado por la Conadep se quería profundizar en lo ocurrido a los desaparecidos. En una carta enviada por Conte a los distintos organismos de derechos humanos, se enfatiza:

transcurrido el episodio CONADEP, el Movimiento debía plantearse una nueva etapa, en la cual es preciso incluir la posibilidad de acciones conjuntas detrás de reclamos que son generales [...]. Entre los pasos que tenemos por delante, uno de los más significativos es la eventual formación de una Comisión Investigadora en la Cámara de Diputados. En tal sentido se preparó un segundo proyecto, que parte del reconocimiento de la tarea cumplida por la CONADEP. La Comisión propuesta se limita ahora a la Cámara Baja, por cuanto en la Alta el manejo es mucho más complicado. (Documento C4. 142. "Carta del diputado Augusto Conte a los organismos de derechos humanos, 7 de febrero de 1985", Archivo APDH)

No cabe duda de que el gran logro político de Alfonsín fue el juicio a la Junta Militar iniciado en abril de 1985. Fue un proceso que sin el trabajo de la Conadep no habría sido posible. En este acontecimiento todos los partidos políticos de oposición apoyaron la decisión gubernamental de enjuiciar a los máximos jerarcas militares por las violaciones a los derechos humanos. Igualmente, el conjunto de los organismos de derechos humanos alabó esta medida de Alfonsín, vista la incapacidad que tenían los tribunales militares en condenar a sus compañeros. Era la primera vez en la historia universal que se juzgaba en democracia a militares de tan alta graduación. ${ }^{7}$

Las razones por las que se procesó a la Junta Militar fueron: asesinatos, torturas, detención clandestina y robos ocurridos entre 1976 y 1982. Las desapariciones no pudieron ser juzgadas porque ese delito no se contemplaba en la legislación argentina puesto que, según la justicia argentina, para que exista un crimen tiene que hallarse el cuerpo de la víctima (Ciancaglini y Granovsky 1995).

Los únicos antecedentes similares fueron el juicio de Nüremberg (agosto 1945 a octubre 1946) contra los jerarcas nazis en 1946 y el 'Juicio a los Coroneles' de 1975 realizado en Grecia por el golpe de estado que habían encabezado en 1967. 
Vol. XXII / № 2 / 2008 / 67-99

\section{La reacción de los partidos políticos frente al informe de la CNVR en Chile}

El debate político en torno al informe de la CNVR había sido bastante intenso durante los meses de su elaboración. Esta circunstancia hizo que la presentación hecha por Aylwin el 5 de marzo fuera seguida con mucho interés por la totalidad de los partidos políticos, tal como recogía la prensa detalladamente durante aquellas semanas.

Las principales discusiones, en lugar de centrarse en la gravedad de las violaciones a los derechos humanos, se polarizaron sobre la interpretación de los hechos y el clima político-social que se vivía momentos previos al golpe de 1973.

Por un lado estaba la oposición de izquierda a la Concertación, entre los que se encontraron el Partido Comunista y lo que quedaba del Movimiento de Izquierda Revolucionaria (MIR), los que, haciendo un reconocimiento de los logros del informe, también lanzaron sus críticas. Por otro lado estaba la actitud de los partidos de la Concertación que formaban gobierno. En una tercera posición se ubicó Renovación Nacional, dentro de la derecha, que reconoció de manera general como positivo el informe. En una cuarta posición estaba la UDI, más aprensiva con el contenido del marco histórico, pero reconociendo la gravedad de las violaciones a los derechos humanos. En cualquier caso, casi todos los partidos mostraron actitudes no muy bien definidas según fuera la persona que intervenía.

El MIR emitió una declaración pública nada más conocer el informe en febrero, una vez que le fue entregado al Presidente Aylwin, si bien todavía nadie conocía su contenido: "No nos cabe duda que para amplios sectores de la población, que no sufrieron en forma directa el terror dictatorial, el Informe Rettig será novedoso e impactante, ya que por primera vez la existencia del terrorismo de Estado será reconocida y acreditada [...]" ("Declaración pública de la Comisión Política del MIR ante el informe de la Comisión Verdad y Reconciliación. Febrero 1991”, Archivo Vicaría de la Solidaridad).

Las críticas emitidas hacia el informe fueron en general las mismas que las de los meses en los que tuvo existencia la comisión:

En este sentido, el Informe Rettig no puede ser el punto final en el conocimiento de los crímenes cometidos por la dictadura militar. Es preciso conocer la verdad no sólo acerca de los detenidos desaparecidos, sino también acerca de los asesinados en falsos enfrentamientos, los torturados, los encarcelados, los exiliados. Y es necesario no sólo conocer la identidad de las víctimas, sino también la de los verdugos y la de los responsables, cómplices, autores intelectuales o encubridores institucionales, políticos y morales. ("Declaración pública de la Comisión Política del MIR ante el informe de la Comisión Verdad y Reconciliación. Febrero 1991”, Archivo Vicaría de la Solidaridad) 
El Partido Comunista reconoció positivamente el esfuerzo de Aylwin en la búsqueda de la verdad. ${ }^{8}$ La secretaria del partido, Gladys Marín, expresó: "Valoramos el alto significado moral y político de la alocución del Presidente Aylwin" (El Siglo, marzo 10-16; tercera época No 66, 1991:8). No obstante, el PC también criticó el informe. El 4 de marzo, un día antes de su presentación, el PC convocó un homenaje a todas las víctimas de la dictadura (El Siglo, marzo 10-16; tercera época No 66, 1991). Por un lado, el PC estaba descontento de haber sido excluido a la hora de elaborarse el informe, ya que fue uno de los partidos más afectados por las violaciones de los derechos humanos. Por otro lado, se criticó el no haber incluido los nombres de responsables, lo que para el PC era una muestra del no querer acabar con la impunidad de tales personas. El PC consideró que se trataba de una decisión muy delicada, pues ello podría resultar en que familiares y víctimas de violaciones a los derechos humanos optaran por hacer justicia por su propia mano. Un tercer aspecto fue la permanencia de personalidades clave de la dictadura en la Corte Suprema, las FFAA, el Senado y algunos otros cargos públicos. Gladys Marín destacó: "Tienen que renunciar los participantes de los crímenes, sean militares o civiles. Los integrantes de la Corte Suprema, los Senadores designados, varios de ellos son culpables directos [...]. Es una verdadera provocación a la democracia naciente que se nos obligue a aceptar a Pinochet como Comandante en Jefe del Ejército" (El Siglo, marzo 10-16; tercera época № 66, 1991:8).

Todos los partidos de la Concertación (Partido Democratacristiano -PDC-, Partido Socialista -PS-, Partido Por la Democracia -PPD- y Partido Radical -PR-) apoyaron el contenido del informe, aunque la mayor parte de sus declaraciones eran respuestas a los comentarios que hacían del trabajo de la comisión los partidos de derecha.

El partido de gobierno que realmente definió la comisión fue la DC. No sólo porque el creador de ella era Aylwin, sino porque varios de sus integrantes eran del PDC, como Jaime Castillo, Jorge Correa o Mónica Jiménez.

En el debate parlamentario sobre el Informe Rettig, el diputado Baldemar Carrasco habló a nombre de la DC. Algunos de sus comentarios más resonantes respecto del tema fueron:

Nadie tiene derecho hoy a usar el tema de los derechos humanos y el Informe de la Comisión para obtener mezquinas prebendas políticas, para orquestar campañas contra instituciones o personas, para perseguir venganzas, buscar víctimas expropiatorias, azuzar movimientos golpistas o justificar actitudes violentistas o terroristas [...]. Compartimos plenamente las decisiones del Presidente de la República entregadas en su mensaje al país, dando cuenta del

8 El Partido Comunista había sido legalizado en octubre de 1990 después de presentar al Registro Electoral 61.483 fichas de afiliados. Para profundizar en la historia del Partido Comunista de Chile, véase: Riquelme Segovia (2003). 
Informe Rettig. Sabemos el valor de la reparación moral y el hondo significado que tiene para la familia del ofendido. Por eso, estamos por apoyar todas las iniciativas que perpetúen la memoria de las víctimas. (Biblioteca del Congreso Nacional s/f:4.351)

El PS, el que fuera uno de los más perseguidos por la dictadura, apoyó plenamente la postura del Mandatario. El presidente del partido, Jorge Arrate, destacó: "Son palabras que confirman una vez más la altura moral del Presidente Aylwin; su marcada sensibilidad por los derechos humanos y su compromiso con la causa de los derechos humanos para que en Chile no vuelva nunca más a ocurrir lo que ocurrió" (Las Últimas Noticias, 5 de marzo de 1991).

El PPD, en voz de Jorge Schaulsohn, apoyó de manera total y ecuánime a Aylwin una vez que presentó el informe al pueblo de Chile. El PPD insistía además en que la Ley de Amnistía no debía impedir la investigación de las violaciones a los derechos humanos. El PPD eligió al diputado Jaime Estévez para expresar la postura del partido. Estévez reconoció el rol de la CNVR, aprovechando la ocasión para reiterar lo que había sido realmente la represión: "Cuando más de dos millares de chilenos son eliminados sin proceso; cuando decenas de miles más padecen formas aberrantes y brutales de torturas, y cuando a lo largo de 16 años y medio se asiste a la acción discrecional de los aparatos de seguridad, estamos frente al fenómeno conocido como terrorismo de Estado" (Biblioteca del Congreso Nacional s/f:4.337-4.338).

El PR mostró en todo momento su apoyo a la CNVR por formar parte de la misma Concertación. No cabe duda de que el hecho de ser Raúl Rettig el presidente de la comisión, antiguo miembro del PR, favoreció tal situación. El 14 de marzo, el diputado radical Mario Devaud señaló:

Nuestro partido asume como condición sine qua non, que el Informe Rettig en sí constituye un principio de reivindicación histórica que la sociedad chilena entera debe a las víctimas de violaciones a los Derechos Humanos; pero que, a la vez, al quedar al descubierto las iniquidades de la vulneración sistemática de los derechos de las personas, recogidas con tanta exhaustividad por la Comisión, queremos que el Informe sea la base de una profunda reflexión de toda la sociedad y el antecedente del reconocimiento unánime del valor que como seres humanos tenían las víctimas, cuya sangre derramada los eleva más allá de toda consideración subordinada o secundaria en cualquier juicio sereno. Biblioteca del Congreso Nacional s/f:4.358)

Renovación Nacional (RN) estuvo de acuerdo con el tono empleado por Aylwin a la hora de mostrar el informe. Los puntos en los que se centró RN fueron en cómo las violaciones a los derechos humanos fueron causadas por el terrorismo político, y que el 
desgastamiento de la democracia de 1973 era de responsabilidad colectiva (La Tercera, 5 de marzo de 1991). La postura definitiva de RN fue expuesta posteriormente en la Cámara de Diputados por Alberto Espina, quien enfatizó los aspectos más positivos del informe en lo siguiente:

La Comisión establece clara e inequívocamente que las violaciones a los derechos humanos las cometen por igual los agentes de servicios de seguridad y los terroristas, los que reprimen y los que subvierten, apartándose de la legalidad y despreciando la vida humana [...]. Las víctimas... sin distinción, merecen nuestro respeto, nuestro recuerdo y nuestro compromiso de reivindicar su honor y su dignidad como seres humanos [...]. Los abusos y excesos cometidos por agentes del Estado durante el gobierno militar y los actos de terrorismo perpetrados por grupos extremistas, no tienen justificación. Tampoco es aceptable la hipótesis de que tales abusos a los derechos de las personas tendrían justificación en un supuesto o real período de guerra. Ello, por cuanto incluso la guerra envuelve límites éticos y jurídicos para los contendientes. (Biblioteca del Congreso Nacional s/f:4.347-4.348)

La UDI adoptó en los días inmediatos a la entrega del informe una reacción considerablemente suave y favorable. Sobre la cuestión de los desaparecidos, el senador Jaime Guzmán destacó: "ese es uno de los puntos más importantes que quedan pendientes, ya que se trata de una cuestión netamente humana” (El Mercurio, 6 de marzo de 1991). Sin embargo, con el pasar de los días y según fueron analizando más minuciosamente los contenidos del informe, la UDI fue tomando una actitud más dura. En una nueva entrevista realizada el 10 de marzo a Guzmán, señaló lo siguiente:

lo que afirmo es que la responsabilidad principal del grueso de las violaciones a los derechos humanos ocurridas en la etapa posterior al 11 de septiembre corresponde a quienes desataron la situación de guerra civil, más que a aquellos militares que cometieron esos actos como parte de la difícil tarea de conjurar la guerra civil [...]. Los máximos dirigentes de la Unidad Popular tienen una responsabilidad todavía mucho mayor en los dolores que sufrieron sus seguidores, como resultado del cuadro de guerra civil al cual los arrastraron. (El Mercurio, 10 de marzo de 1991)

En la misma entrevista, Guzmán destacó que la disolución de la Dina se produjo en cierta medida gracias a él, lo cual fue un acierto de Pinochet. Guzmán rechaza que se investiguen los casos de violaciones a los derechos humanos ocurridos dada la vigencia de la Ley de Amnistía, la cual según él "borra el delito y, en consecuencia, acreditado que el hecho punible se cometió en el período cubierto por la amnistía, no cabe investigación 
del culpable" (El Mercurio, 10 de marzo de 1991). La firmeza de Guzmán para no procesar a los responsables de la represión y su insistencia en culpar a la Unidad Popular por situación caótica previa al golpe, coincide claramente con los argumentos del propio Pinochet. Esto se convirtió en un argumento más para ser asesinado semanas más tarde, el 1 abril, cuando salía de su clase de Derecho Constitucional en el Campus Oriente de la Universidad Católica (Loveman y Lira 2002:89). De este modo: "Cet assassinat brise l'élan de la commission Rettig, l'armée de terre accusant le terrorisme de chercher à détruire la Nation chilienne, et ne considérant plus comme d'actualité une réaction officielle au rapport" (Patino 2000:270). ${ }^{9}$ El propio Pinochet, asustado por el asesinato de su principal asesor, se dirigió a Aylwin para expresarle su temor, pero también para proponer la idea de delegar en el Ejército la lucha contra el terrorismo:

el país se encuentra sometido a una grave agresión violentista, la que fundamentalmente se materializa a través del terrorismo selectivo. Tal situación, de acuerdo a la doctrina militar, constituye una etapa importante de la guerra subversiva, enmarcada en la fase de violencia sistemática, cuyos efectos podrían ser dramáticos para los intereses nacionales [...]. En consecuencia, tratándose de una situación de corte netamente militar, el Ejército hizo presente que [...] podría concurrir con sus medios especializados en beneficio de los esfuerzos que desarrolle el gobierno para erradicar este flagelo que perjudica a la nación chilena. (Documento 007065, "Oficio reservado del Comandante en Jefe a Patricio Aylwin del 5 de abril de 1991", Archivo Corporación Justicia y Democracia)

Ante lo cual, el Presidente Aylwin le respondió con firmeza. En la carta le hacía saber al comandante en jefe cómo la Constitución que él mismo había creado en 1980 no le permitía interferir en asuntos internos de seguridad:

el Gobierno [...], está organizando, en el Ministerio del Interior, un equipo de trabajo que encabece esta tarea, especialmente en ámbito de inteligencia; que, por mandato expreso de la Constitución, las funciones de Seguridad corresponden a Carabineros e Investigaciones y no a las instituciones de la Defensa Nacional; que yo espero de éstas su cooperación con la participación de miembros suyos en ese equipo de trabajo, pero que no se trata en ningún caso, de crear una nueva C.N.I. (Documento 007066, "Carta del Presidente Aylwin al Comandante en Jefe, 6 de abril de 1991", Archivo Corporación Justicia y Democracia)

9 'Este asesinato destrozó el impulso de la Comisión Rettig, el Ejército de tierra acusó al terrorismo de buscar la destrucción de la nación chilena sin considerar como tema de actualidad una reacción oficial al informe’. (Traducción propia.) 
No obstante, semanas antes, mientras se debatía el informe en el Congreso el 14 de marzo, la UDI mostró su postura definitiva. A través del diputado Juan Antonio Coloma, la UDI criticó moderadamente el informe. Poco después, el también diputado gremialista Francisco Bartolucci lo hizo de manera más dura. Al final del debate parlamentario, la UDI tuvo que precisar que la posición oficial era la de Coloma, quien entre varias cosas destacó:

\begin{abstract}
gravitante aporte que el citado Informe Rettig realiza respecto a lo que se consideran violaciones a los derechos humanos, al desecharse la arbitraria teoría en cuanto que ellos sólo atendían a los excesos que cometían agentes del Estado, ampliándose dicha concepción a cualquier atropello a la dignidad humana, independiente de quien la ejecuta, con lo que se incluyen, por cierto, los actos terroristas [...]. Nada de lo contenido en el Informe Rettig habría ocurrido, si en Chile no hubiera existido una dirigencia que desatara una odiosidad irreconciliable y el caos moral, político y económico entre los chilenos, en los inicios de la década del setenta. (Biblioteca del Congreso Nacional s/f: 4.3544.355)
\end{abstract}

Una nueva polémica resultó de las opiniones de las FFAA y Carabineros sobre el informe, expuestas el 28 de marzo ante el Consejo de Seguridad Nacional. Los partidos de izquierda y de la Concertación lamentaron la actitud castrense en relación al tema, rechazando sus tesis exculpatorias.

La derecha, por el contrario, compartió buena parte de los planteamientos de las Fuerzas Armadas: "la colectividad opositora expresó su coincidencia con la tesis planteada por el Ejército y la Armada en el sentido de que en Chile hubo una guerra interna deliberadamente por la Unidad Popular" (El Mercurio, 29 de marzo de 1991).

El gobierno, una vez reunido el Consejo de Seguridad Nacional, dio por terminado el debate político sobre el informe de la CNVR. El Poder Ejecutivo lamentó públicamente que Pinochet hubiera hecho uso de comentarios del mismo Presidente Aylwin emitidos en 1973 en los que se culpó al gobierno de la Unidad Popular de la necesidad de dar el golpe (La Nación, 29 de marzo de 1991).

La última crítica importante al informe de la CNVR provino de la Corte Suprema, el 13 de mayo, por medio de un comunicado público en el cual se lo calificaba de "temerario y tendencioso". Este acuerdo fue firmado por 15 de sus 17 miembros, exceptuándose la participación del presidente de la Corte Suprema, Luis Maldonado, y de su vicepresidente, Rafael Retamal. La Corte consideraba que el informe "colocaba a los jueces en un plano de responsabilidad casi a la par con los propios autores de los abusos contra los derechos humanos" (El Mercurio, 16 de mayo de 1991). Además, destacaba: "la Corte Suprema de Justicia no puede aceptar como válido el enjuiciamiento de los tribunales, por una entidad que carece totalmente de la más insignificante facultad para hacerlo, 
pero que en su afán de divulgar una absurda crítica, no trepida en violentar el ámbito de sus atribuciones" (El Mercurio, 16 de mayo de 1991).

La mayor parte de los miembros de la Corte Suprema había sido designada por Pinochet meses antes de su salida del gobierno para dificultar posibles procesamientos contra miembros de las FFAA y Carabineros (Ensalaco 2002). Para ello, Pinochet eligió a personas de confianza que se habían destacado por su fidelidad. La respuesta de la Corte Suprema se produjo fundamentalmente por haber tomado las conclusiones de la CNVR como un ataque directo a sus integrantes.

\section{La ciudadanía: el beneplácito de la verdad}

Con la entrega de los informes, las sociedades de Argentina y Chile descubrieron la verdad de las violaciones a los derechos humanos. El hecho de que la información procediera del gobierno, imputaba una oficialidad y respetabilidad a los informes que difícilmente podrían haberse cuestionado. Igualmente, la atención mediática de los informes fue mucho mayor que aquella información expuesta por los organismos de derechos humanos durante los años anteriores, lo que hacía que su alcance fuera mucho más masivo. Así, al conjunto de las sociedades les resultó muy complicado mantenerse al margen del debate.

Los informes fueron escritos principalmente para que las sociedades comprendieran cómo había operado la represión. Asimismo, fueron premeditadamente elaborados según el efecto que se quería causar en su destinatario. Esta singularidad condicionó el contenido de los informes para que fueran aceptados de manera masiva, sin crear polémica con el gobierno y mucho menos generar divisiones.

\section{La ciudadanía frente al Nunca más en Argentina}

El mismo día en que la Conadep entregó el informe al Presidente Alfonsín, una multitud de unas 70.000 personas se concentró frente a la Casa de Gobierno para exigir el castigo de los culpables. Hasta el momento fue la manifestación más grande de la nueva etapa institucional (Tiempo Argentino, 21 de septiembre de 1984). Actos semejantes de apoyo a la labor de la Conadep se reprodujeron por toda Argentina. En Córdoba, segunda ciudad más grande de Argentina, se congregaron para la ocasión unas 10.000 personas (Clarín, 29 de septiembre de 1984).

El informe de la Conadep impactó fuertemente en la sociedad argentina, pues lo que en él se narraba había ocurrido en la vida de cada ciudadano. Según Leis: 
A partir del trabajo de la CONADEP se produce un cambio cualitativo en la conciencia de la gente. No queda nadie en la Argentina que no pueda darse por enterado de lo ocurrido durante el terrorismo de Estado. El NUNCA MÁS se transforma en una nueva consigna. No hay razón de Estado que pueda justificar o atenuar lo actuado por las fuerzas armadas. (Leis 1997:41-42)

Si bien no se realizaron encuestas que midieran la aceptación del informe de la Conadep en el país, se puede observar que su difusión fue tremendamente masiva y reconocida por altísimos porcentajes de la sociedad. Según Roniger y Sznajder: "The report had the credibility of an impartial source, independent of the traditional political forces and representing all sectors of civilian society" (Roniger y Sznajder 1999:63). Sin embargo, la atención de los medios de comunicación respondía a una demanda generada por el alto interés que había causado el tema de los desaparecidos una vez que se produjo la entrega del Nunca más. No se mantuvo la más mínima sensibilidad por los familiares ni por los sobrevivientes de la represión. Según Calveiro:

Restos humanos exhumados, niños cuyos padres habían desaparecido, rostros de familiares angustiados hasta las lágrimas eran la prueba visible de una realidad tan conocida como negada. El impacto de las imágenes brutales se amortiguaba y se pervertía exhibiéndolas a la vuelta de página de las modelos más cotizadas del año. Los testimonios de sobrevivientes o de torturadores arrepentidos y confesos, podrían dar lo mismo, en todo caso garantizaban un alto porcentaje de ventas. (Calveiro 2001:162)

Quienes consideraron el informe de improcedente fueron buena parte de las FFAA y sus antiguos colaboradores de la época de la dictadura, pero en términos porcentuales poblacionales estos suponían cifras muy bajas.

En cualquier caso, a la sociedad argentina le resultó duro asumir su pasado, razón por la que acepta explicaciones de la 'teoría de los dos demonios' y la 'teoría de las víctimas inocentes' escrita por Sábato en el prólogo del informe, donde destaca que la sociedad argentina había sido arrastrada por el terrorismo de izquierda por un lado, y por otro lado la represión del estado militar. ${ }^{10}$ Frente a ello, Cohen sostiene: "la sociedad, producto de un proceso de autojustificación, niega su responsabilidad en lo sucedido porque no puede percibirse a sí misma como perpetradora de injusticias ya que eso debilitaría la imagen que tiene de sí misma y que proyecta al mundo" (2001:25).

Con el informe, la sociedad se convirtió en víctima de las estrategias de ambos grupos, sin dejar constancia alguna del apoyo que dieran tanto a los movimientos guerrilleros

10 Según Vezzetti, "una sociedad que ha encontrado en la figura de los demonios la confirmación de su inocencia y su ajenidad frente a la barbarie que se desplegaba ante sus ojos" (2002:15). 
durante el principio de los años setenta o la colaboración que prestaron a los militares una vez que asumieron el poder con el golpe de estado de 1976. En este tema, Vezzetti se opone a la tesis del Nunca más y reivindica el protagonismo y la responsabilidad de la sociedad argentina:

si bien es claro que las responsabilidades colectivas no se confunden con las culpabilidades ante la ley, me interesa destacar que una sociedad es responsable no sólo por lo que activamente promueve y apoya sino incluso por aquello que es incapaz de evitar. La dictadura no fue impuesta por fuerzas extrañas y completamente ajenas a tradiciones, acciones y representaciones de la lucha políticas que estaban presentes en la sociedad desde mucho antes. Fue promovida por una escalada de violencia ilegal, facciosidad y exaltación antiinstitucional que involucró a un amplio espectro de la sociedad civil y política, en la derecha tanto como en la izquierda. (Vezzetti 1999:41)

Contrariamente, una vez recuperada la democracia, la sociedad argentina no reconoció su grado de responsabilidad en las violaciones a los derechos humanos cometidas durante el proceso. Se prefirió repudiar cualquier tipo de violencia, viniera de donde fuera, que tomar una posición doctrinaria al respecto. Se fusionó la memoria de la actuación de los grupos violentos de extrema izquierda con la represión emprendida por las FFAA y de Orden (González 1995).

El Nunca más fue el instrumento clave para dar paso al juicio de la Junta Militar. Con los hechos narrados y difundidos públicamente de manera oficial, la sociedad optó por aumentar la presión al gobierno para procesar a los responsables. Claramente, Alfonsín no fue consciente de las consecuencias sociales que tendría el Nunca más, ya que su abrumadora respuesta le exigió llevar a los miliares a la Corte Civil, cosa que en un principio no tenía pensado hacer. Fue evidentemente un error de cálculo. Así, según Verbitsky: "El gobierno creó la Conadep como contrafuego para que el interés de la sociedad civil en intervenir en el esclarecimiento de los trágicos episodios en los que desaparecieron miles de personas [...] no se propagara impulsado por el viento de la movilización popular capaz de inflamar la oratoria parlamentaria" (Verbitsky 2004:52).

En el informe se encontraban miles de casos de violaciones a los derechos humanos y en la documentación recopilada durante sus nueve meses de trabajo aparecían las pruebas necesarias para inculpar a cualquier miembro de las instituciones armadas que hubiera colaborado en la represión. 


\section{La ciudadanía frente al informe de la CNVR en Chile}

Los datos que se narraban en el informe de la CNVR no eran nuevos para la sociedad chilena, pero el impacto fue alto dada la oficialidad del medio en el que se trasmitía la información. Los autores más escépticos con el gobierno consideraron que el alcance del informe de la CNVR no fue tal, pues como dice Elgueta: "las investigaciones realizadas en los tribunales y el propio Informe Rettig [...] no fueron suficientes para establecer una verdad completa y contrarrestar la negación y manipulación" (2000:35). El 7 de febrero se difundió una encuesta en la que se preguntaba si el Informe de la CNVR contaba toda la verdad de lo sucedido. ${ }^{11}$ El resultado fue el siguiente:

¿Cree usted que el informe da cuenta de toda la verdad de lo sucedido?

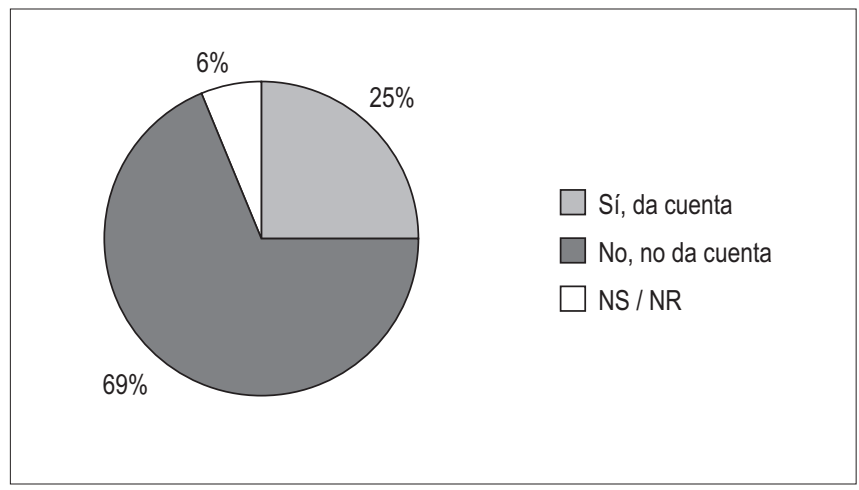

Fuente: La Segunda, 7 de marzo de 1991.

En el resultado cabe resaltar que la mayoría de los entrevistados consideraba que el informe no relataba la totalidad de la verdad acerca de las violaciones de los derechos humanos en Chile.

Asimismo, el Centro de Estudios Públicos (CEP) efectuó en el mes de marzo unas encuestas sobre los efectos del informe de la CNVR. Los resultados fueron:

11 La encuesta fue realizada por la empresa BASICA S.A. entre sectores alto, medio y medio-bajo de la Región Metropolitana que incluía al $91 \%$ de su población. El sondeo fue realizado por teléfono. 
Vol. XXII / № 2 / 2008 / 67-99

¿Cómo ha sido la posición de Aylwin frente al problema de los derechos humanos?

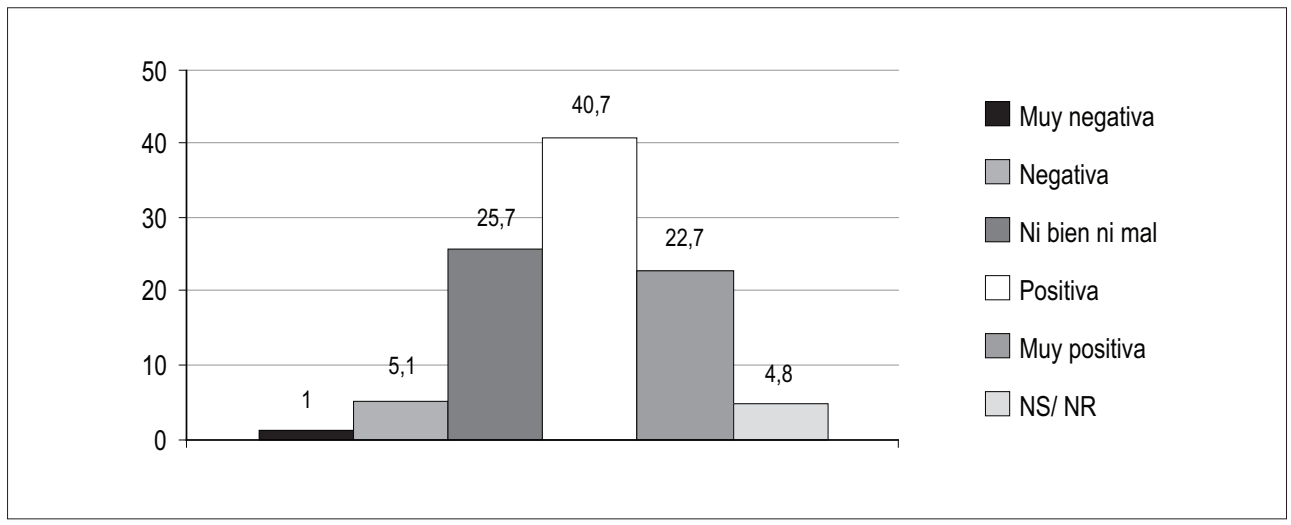

Fuente: Centro de Estudios Públicos (1991).

Se puede observar que los resultados de la encuesta son muy favorables para Aylwin, ya que un total del 63,4\% de la muestra aprueba su empeño en los derechos humanos, frente a un $6,1 \%$ que no lo considera así. Posteriormente se consultó:

¿El informe de la CNVR será beneficioso o perjudicial para Chile?

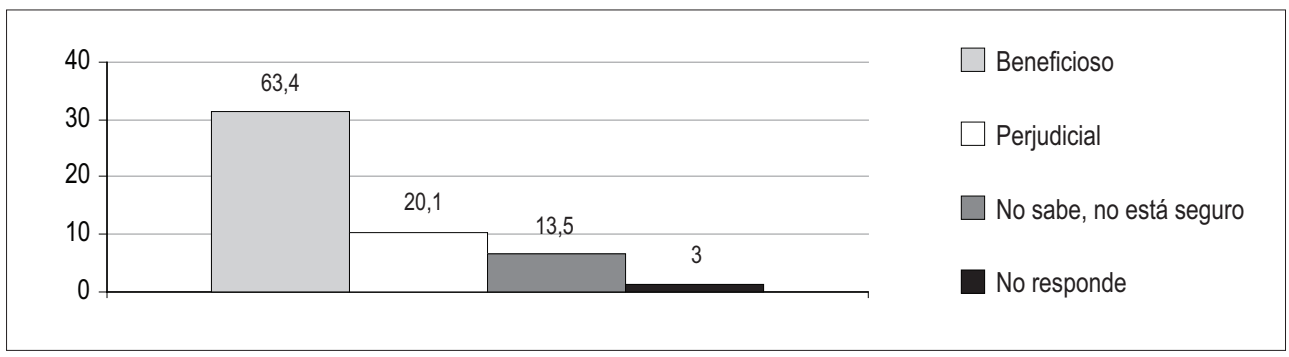

A partir de estos gráficos se observa que la mayor parte de la sociedad consideraba que los resultados del informe serían positivos. Esto se correspondía en buena parte a su contenido, dada la gravedad de los hechos que se relataban allí. De especial significación fue el condenar por igual los atentados con resultado de muerte perpetrados por grupos violentos de extrema izquierda opositores a la dictadura con las violaciones a los derechos humanos cometidos por las FFAA. 
Una diferencia sustancial con respecto al Nunca más es que el informe de la CNVR incluye análisis de la actitud de la sociedad chilena durante las distintas fases de la represión. En el informe se hacen considerables categorías, entre las que se destacan los opositores al régimen, los colaboradores, Iglesias de diversas confesiones y los organismos de derechos humanos. En el informe se muestra que la reacción general de la sociedad no fue organizada en la primera mitad de la dictadura, siendo a partir de 1983 cuando la defensa de los derechos humanos se fue potenciando cada vez más. ${ }^{12}$ Del período inmediato al golpe de 1973, el informe destaca: "No prevaleció, pues, en nuestra patria, la convicción profunda de que toda persona debe ser respetada en sus derechos humanos, en especial aquellos más esenciales, cualesquiera sea el cargo que se le impute o el daño que supuestamente haya causado" (CNVR 1996:442).

En relación al período siguiente, comprendido entre 1978 y 1983, en el informe añade:

En general no se observó todavía una reacción significativa del cuerpo social
en su conjunto que mostrara una disposición abiertamente solidaria con las
víctimas de las violaciones, manteniéndose al respecto una actitud más bien
indiferente o de incredulidad, no obstante una progresiva aunque lenta toma
de conciencia sobre el tema, impulsada por sucesos como el descubrimiento
de cuerpos de un grupo de detenidos desaparecidos en una mina de Lonquén,
que el gobierno, en información a los organismos internacionales, había dado
por muertos y entregados al Instituto Médico Legal cinco años antes. (CNVR
1996:745-746)

En este aspecto cabe destacar que la situación fuera de Chile era diferente. Los militantes o simpatizantes de la Unidad Popular (UP) denunciaron desde el primer momento y desde el exilio las violaciones a los derechos humanos que se estaban cometiendo en el país a través de importantes campañas, las cuales contaban con el respaldo de la comunidad internacional.

La sociedad opositora a la Unidad Popular encontró las causas del golpe de estado y de la represión en la inestabilidad político-social del período 1970-1973. Esta misma idea se transmitió en el marco histórico del Informe Rettig para justificar el silencio de la sociedad durante los primeros años, al igual que lo hizo el Nunca más a partir de la 'teoría de los dos demonios' de Sábato. Según Lefranc: "Les victimes, les organisations de défense des droits $\mathrm{d}$ l'homme, certains partis politiques les ont le plus souvent rejetées;

12 Sin embargo, ante estos comentarios, en el informe se hace la siguiente advertencia: "No nos corresponde pronunciarnos sobre la responsabilidad moral que pueda caber a la sociedad en su conjunto como consecuencia de su falta de reacción oportuna y enérgica frente a lo que estaba ocurriendo" (CNVR 1996:442). 
mais la majorité des populations des pays concernés les a acceptées, silencieusement [...]" (Lefranc 2002:11). ${ }^{13}$

Por el contrario, el informe de la CNVR fue el instrumento que concienció de manera masiva a la sociedad chilena de la necesidad de procesar a los responsables de las violaciones a los derechos humanos por la gravedad de los hechos que en él se narraban. ${ }^{14}$ En la documentación elaborada por la CNVR durante los nueve meses de su funcionamiento se encontraban pruebas más que suficientes para llevar a juicio a muchos de los militares involucrados en la represión. A diferencia del caso argentino, la justicia en Chile fue mucho más lenta en llamar a los uniformados a declarar. Las razones principales se encontraban en la vigencia de la Ley de Amnistía, la continuación de jueces designados por el mismo Pinochet en la Corte Suprema o la permanencia en la Comandancia del Ejército del antiguo dictador. Como señala Portales, "la conciencia moral de la nación chilena recibió un nuevo golpe devastador” (Portales 2000:95). La mayor parte de la sociedad chilena se sentía todavía incapaz de resolver los problemas del pasado por la obstrucción del antiguo dictador.

\section{Conclusiones}

En este artículo se han presentado las reacciones que ocasionaron los informes de la Conadep y la CNVR en los distintos sectores durante los procesos de transición a la democracia en Argentina y en Chile. Los sectores aquí analizados fueron conscientes de la importancia que tenían los informes para la historia de los dos países. Se trató de una verdad en la que cada sector intentó incidir en función de sus intereses. Además, se añade el propósito de todos ellos de recibir la categoría de víctima. No obstante, para ese momento los informes habían establecido una verdad. Nada se podía hacer ahora para cambiarla. Sólo quedaba la alternativa de responder públicamente para dejar constancia de la opinión que se tenía de los trabajos de las comisiones.

El principal logro de los informes en Argentina y Chile fue el de concienciar a la sociedad respecto de la gravedad de las violaciones a los derechos humanos que se cometieron durante las dictaduras militares. La oficialidad de las comisiones favoreció el reconocimiento de las víctimas desde cualquier posición política y social. Además, los informes produjeron que sectores importantes de la sociedad exigieran a los respectivos

13 'Las víctimas, las organizaciones de derechos humanos y ciertos partidos políticos las han rechazado continuamente; pero la mayoría de la población de dichos países las han aceptado silenciosamente’. (Traducción propia.)

14 El mismo Aylwin señala el cambio producido por el informe de la CNVR: "La opinión pública tomó conciencia de lo ocurrido y valoró su gravedad. Quienes no creían hasta entonces que las acusaciones sobre violaciones a los derechos humanos $y$, especialmente, sobre desaparecimientos de personas detenidas fueran fundadas, tuvieron que admitirlas" (Aylwin 1996:45). 
gobiernos emprender acciones contra los responsables de la represión. En muchos casos se pasaron a retiro a varias de las personas vinculadas en forma directa a las violaciones a los derechos humanos. Como se comentó previamente, antes de abandonar la Presidencia de Chile, Pinochet había dejado instalados los instrumentos legales necesarios para que ello no pudiera realizarse. En Argentina, el número de funcionarios que trabajaron para el régimen militar era demasiado alto, por lo que el gobierno consideró peligroso para la nueva democracia reemplazar a todos de sus puestos y, como consecuencia, el alcance de los informes para procesar a la totalidad de los responsables fue limitado.

Los informes son el producto final de las comisiones, y estuvieron sometidos a un proceso largo, complejo y lleno de polémica. Simultáneamente, los informes presentaron una memoria oficial de la represión, muy condicionada a aquello que desde la Presidencia se quería transmitir a la población y también de lo que realmente se pudo averiguar. Al establecerse una verdad global, muchos aspectos de la represión no fueron profundizados en los informes. Por ejemplo, además de no señalar a los responsables de las violaciones a los derechos humanos, tampoco se incluyeron los otros efectos que causó la represión como la tortura, el exilio o la prisión política.

Consecuentemente, se puede constatar que los informes no sólo confirmaron la represión, sino que también fueron instrumentos que alteraron de manera considerable la vida nacional de Argentina y Chile. Así, los informes significaron un antes y un después en dos países, es decir, construyeron las bases para la reconstrucción histórica de las violaciones a los derechos humanos que más se han consultado. Por ello, y a pesar de las limitaciones con las que fueron escritos, contienen un alto valor historiográfico. Posteriormente, la Conadep y la CNVR han servido de ejemplo para la creación de distintas comisiones de la verdad en América Central y Sudáfrica, donde expertos argentinos y chilenos acudieron en calidad de asesores. Inclusive en Chile, la CNVR fue la base para la creación, en el año 2003, de la Comisión Nacional de Prisión Política y Tortura, cuyo objetivo principal fue estimar el número de víctimas que lograron sobrevivir el horror con el fin de hacerles un reconocimiento oficial. La cifra presentada fue de 28.459 casos, a pesar de que los propios comisionados consideraron que la realidad se acercaría a los 100.000 dada la enorme cantidad de gente que no presentó su testimonio.

Con esta investigación se demuestra que la Conadep y la CNVR presentaron una idea aproximada, pero minimizada, del alcance de la represión impuesta durante los regímenes militares en Argentina y Chile. Igualmente, frente a esta realidad aparecieron las voces de quienes la negaban o la justificaban a base de su ideología o sus propios intereses, siendo una circunstancia que motiva nuevos estudios académicos sobre las divergencias que todavía hoy prevalecen sobre el pasado. 


\section{Referencias bibliográficas}

Aylwin, Patricio, 1996. "La Comisión Chilena sobre la Verdad y Reconciliación”. Estudios Básicos de Derechos Humanos VII. San José: IIDH, 105-119.

Barahona de Brito, Alexandra, 1997. Human Rights and Democratization. Uruguay and Chile. New York: Oxford University Press.

Biblioteca del Congreso Nacional, s/f. L.P. Diputados. Legislatura Extraordinaria. Octubre 1990Mayo 1991. Tomo 321. Vol. V. Santiago: Alborada S.A.

Bignone, Reynaldo B.A, 2000. El último de Facto II. Quince años después, Memoria y Testimonio. Buenos Aires: Centro de copiado San Miguel.

Calveiro, Pilar, 2001. Poder y desaparición. Los campos de concentración en Argentina. Buenos Aires: Colihue.

Camacho Padilla, Fernando, 2006a. "Una memoria consensuada: el Informe Rettig". En Actas del $5^{\circ}$ Congreso Chileno de Antropología. Tomo II. Santiago: Lom, 1.054-1.062.

2006b. "Los frutos literarios del caso Pinochet". Iberoamericana. Nordic Journal of Latin American and Caribbean Studies, Vol. XXXV, 2, 25-37.

Centro de Estudios Públicos, 1991. "Cuestionario estudio social y de opinion pública. Marzo 1991”. Documento de Trabajo No 156, junio.

Ciancaglini, Sergio, Martín Granovsky, 1995. Nada más que la verdad. El juicio a las juntas. Buenos Aires: Planeta.

CNRR, 1996. Informe de la Corporación Nacional de Reparación y Reconciliación. Santiago: s/e.

CNVR, 1996. Informe de la Comisión Nacional de Verdad y Reconciliación. Santiago: Andros Impresores.

Codepu, 2001. Informe de Derechos Humanos 1990-2000. Santiago: Lom.

Conadep, 1999. Nunca más. Informe de la Comisión Nacional sobre la Desaparición de Personas. Buenos Aires: Editorial Universitaria de Buenos Aires.

Cohen, Stanley, 2001. "La clave es superar las negociaciones". Página 12, 21 de enero de 2001, 25.

Díaz Bessone, Ramón Genaro, 1996. Guerra revolucionaria en la Argentina (1959-1978). Buenos Aires: Círculo Militar.

Elgueta, Gloria, 2000. “Secreto, verdad y memoria”. En Nelly Richard, comp. Políticas y estéticas de la memoria. Santiago: Cuarto Propio.

Ensalaco, Mark, 2002. Chile bajo Pinochet, la recuperación de la verdad. Madrid: Alianza Ensayo. Etchecolatz, Miguel O., s/f. La otra campana del Nunca más. Buenos Aires: s/e.

González, Inés, 1995. "Nunca más, el juicio más allá de los estrados”. En Carlos H. Acuña, comp. Juicio, castigos y memorias: derechos humanos y justicia en la política argentina. Buenos Aires: Nueva Visión, 193-215.

Lefranc, Sandrine, 2002. Politiques du pardon. Paris: PUF.

Leis, Héctor Ricardo, 1997. El movimiento por los derechos humanos y la política argentina. Buenos Aires: Biblioteca Política Argentina. 
Loveman, Brian, Elizabeth Lira, 2002. El espejismo de la reconciliación politica. Chile 1990-2002. Santiago: Lom.

Madres de Plaza de Mayo, 1985. Año 1, No 2, enero.

Marchesi, Aldo, 2005. "Vencedores vencidos: las respuestas militares frente a los informes 'Nunca Más’ en el Cono Sur”. En Felipe Agüero, Eric Hershberg, comps. Memorias militares sobre la represión del Cono Sur. Visiones en disputa en dictadura y democracia. Madrid: Siglo XXI, 194-200.

Patino, Bruno, 2000. Pinochet s'en va... La Transition démocratique au Chili (1988-1994). Paris: IHEAL Éditions.

Portales, Felipe, 2000. Chile: Una democracia tutelada. Santiago: Sudamericana.

Moulián, Tomás, 2000. "La liturgia de la reconciliación". En Nelly Richard, comp. Políticas y estéticas de la memoria. Santiago: Cuarto Propio.

Rama Argentina de la Asociación Americana de Juristas, 1988. Argentina Juicio a los militares. Documentos Secretos, Decretos-Leyes, Jurisprudencia. Buenos Aires: s/e.

Riquelme Segovia, Alfredo, 2003. Comunismo mundial y transición chilena: la incidencia de un fenómeno global en un proceso politico nacional durante el siglo XX. Tesis (PhD). Departamento de Historia, Universidad de Valencia, España.

Roniger, Luis y Mario Sznajder, 1999. The Legacy of Human Rights Violations in the Southern Cone. Argentina, Chile and Uruguay. New York: Oxford University Press.

Vezzetti, Hugo, 1999. "Memorias del Nunca más". Punto de Vista, No 64. 2002. Pasado y presente. Guerra, dictadura y sociedad en la Argentina. Buenos Aires: Siglo XXI, 37-41.

Verbistky, Horacio, 2004. Civiles y militares. Memoria secreta de la transición. Buenos Aires: Sudamericana.

\section{DOCUMENTOS}

Archivo de la Asamblea Permanente por los Derechos Humanos

Documento B.758. "Hacia la verdad y por la justicia".

Documento C4. 142. "Carta del diputado Augusto Conte a los organismos de derechos humanos, 7 de febrero de 1985 ”.

\section{Archivo Corporación Justicia y Democracia}

Documento 002000, "Carta a Patricio Aylwin de la Agrupación de Familiares de Ejecutados Políticos, 11 de junio de 1991”.

Documento 003021.

Documento 007062, "Carta del Comandante en Jefe Augusto Pinochet al Presidente Aylwin”.

Documento 007065, "Oficio reservado del Comandante en Jefe a Patricio Aylwin del 5 de abril de 1991 ”.

Documento 007066, "Carta del Presidente Aylwin al Comandante en Jefe, 6 de abril de 1991". 
Vol. XXII / № 2 / 2008 / 67-99

Archivo de Familiares Detenidos Desaparecidos por Razones Politicas

Documento B8.95. "Por la memoria histórica - contra la impunidad".

Documento C4.36. "Al Presidente de la Comisión Nacional sobre Desaparición de Personas Sr. Ernesto Sábato. 14 de septiembre de 1984”.

Archivo Vicaría de la Solidaridad

Documento 00044.00. "Verdad y reconciliación. Elementos para una reflexión a partir del Informe de la Comisión Verdad y Reconciliación”.

"Declaración pública de la Comisión Política del MIR ante el informe de la Comisión Verdad y Reconciliación. Febrero 1991”.

PRENSA ARGENTINA (revisada entre diciembre de 1983 y enero de 1985, aproximadamente)

Clarin

Diario Argentino

Diario Madres de Plaza de Mayo

Página 12

Tiempo Argentino

PRENSA CHILENA (revisada entre abril de 1990 y mayo de 1991)

El Mercurio

El Siglo

La Época

La Tercera

Las Últimas Noticias 